Portland State University

PDXScholar

\title{
Conceptualizing Social Determinants of Maternal and Infant Health Disparities
}

\section{Susanne Klawetter}

Portland State University, skla2@pdx.edu

Follow this and additional works at: https://pdxscholar.library.pdx.edu/socwork_fac

Part of the Medicine and Health Sciences Commons, and the Social Work Commons Let us know how access to this document benefits you.

Citation Details

Klawetter, S. (2014). Conceptualizing social determinants of maternal and infant health disparities. Affilia, 29(2), 131-141.

This Article is brought to you for free and open access. It has been accepted for inclusion in School of Social Work Faculty Publications and Presentations by an authorized administrator of PDXScholar. Please contact us if we can make this document more accessible: pdxscholar@pdx.edu. 


\title{
Conceptualizing Social Determinants of Maternal and Infant Health Disparities
}

Affilia: Journal of Women and Social Work

20I4, Vol. 29(2) 131-14I

(C) The Author(s) 2014

Reprints and permission: sagepub.com/journalsPermissions.nav DOI: $10.1177 / 088610991351645$ | aff.sagepub.com

(SAGE

\section{Susanne Klawetter'}

\begin{abstract}
Research demonstrates that women and children within marginalized ethnic and racial groups and those living in poverty experience disparate health outcomes. These disparities have immediate and long-term consequences. Exploring two theories used to examine social determinants of healthlife course perspective and historical trauma response, this article will explain the major premises of each, provide application examples, compare and examine utility for practice, and highlight areas for future research. A theoretical critique will be included, as well as insight into how these theories together might address gaps as an approach to maternal and infant health research and practice.
\end{abstract}

\section{Keywords}

cumulative advantage/inequality, health disparities, historical trauma, life-course perspective, social justice

Health disparities for marginalized people within the United States are well documented. Research continues to highlight disparities particularly for women and children within certain ethnic and racial groups and those living in poverty (Braveman, Egerter, \& Mockenhaupt, 2011; Hogan, Rowley, Bennett, \& Taylor, 2012; Walker \& Chestnut, 2010). The effect of these disparities on the lives of children is immediate and, as research indicates, profoundly far reaching across life trajectories (Lu \& Halfon, 2003; Wilensky \& Satcher, 2009).

Individuals living in poverty, African Americans and American Indians and Alaska Natives (AIAN) experience higher rates of infant mortality and low birth weights (Braveman, Egerter, \& Mockenhaupt, 2011; Hogan et al., 2012; Walker \& Chesnut, 2010; Webb, 2004) and higher rates of maternal morbidity and mortality (Walker \& Chesnut, 2010; Webb, 2004). Additionally, Mexican Americans join these groups with disproportionately high rates of chronic health issues such as obesity, cardiovascular disease, and diabetes (Braveman, Egerter, \& Mockenhaupt, 2011; Estrada, 2009), and more mental health conditions such as depression, anxiety, substance abuse, and suicide

\footnotetext{
'University of Denver, Denver, CO, USA
} 
(Cordero \& Kurz, 2006; Estrada, 2009; Evans-Campbell, 2008, Walters, Beltrán, Huh, \& EvansCampbell, 2011; Walters, Mohammed, et al., 2011). For example, in Contra Costa County, California, African Americans experience a $13.4 \%$ low birth weight rate and a $15.4 \%$ preterm birth rate in contrast to a white low birth weight rate of $5.6 \%$ and preterm birth rate of $9.5 \%$ (Pies, Parthasarathy, $\&$ Posner, 2012). These disparate outcomes are reflective of national trends and exist even between whites and African Americans with similar income levels. Several studies have found that whites fair better in maternal and infant health outcomes across income levels, but as white and African American women's income increases, the disparity between their health outcomes widens (Braveman, 2011; Hogan et al., 2012; Lu \& Halfon, 2003). While research has not yet examined maternal and child health disparities for AIAN or Mexican Americans while controlling for socioeconomic status, infant mortality rates among AIAN are $22 \%$ higher than the general U.S. population (Walters \& Simoni, 2002). African Americans and AIAN die 2-4 times as often from pregnancy complications compared to white women (Webb, 2004).

These statistics reflect the effects of structural oppression and the complicated relationship between socioeconomic status, gender, and race and ethnicity. While multiple factors impact maternal and child health, structural oppression manifested as racism, discrimination, and targeted policies to subjugate certain groups (i.e., African Americans, Mexican Americans, AIAN) affect health outcomes for these groups in complex ways including socioeconomic, educational, and cultural marginalization.

Health disparities may be explored from various perspectives; however, many scholars acknowledge that a biomedical approach alone is not sufficient to address health disparities (Sotero, 2006; Tseris, 2013; Walters, Beltrán, et al., 2011; Walters, Mohammed, et al., 2011, Wilensky \& Satcher, 2009). Research documents the lack of health care access and underutilization of health care services by people of color (Burgess, Ding, Hargreaves, van Ryn, \& Phelan, 2008), but disparities persist even in circumstances where health care services are used more equally. For example, in the aforementioned Contra Costa County study, infant health disparities existed despite more equitable use of prenatal services across racial and ethnic groups (Pies et al., 2012). Researching social determinants of health provides an alternative perspective (Braveman, Egerter, \& Mockenhaupt, 2011). Identifying determinants of health is complicated by the dynamic ways in which these factors interact with one another over potentially long periods of time (Ahnquist, Wamala, \& Linstrom, 2012; Braveman, Egerter, Woolf, \& Marks, 2011). Acculturation and immigration status provide examples that illustrate how time complicates the examination of health determinants. Research suggests that the age of arrival as well as the length of time living in the United States relate to health outcomes (Cordero \& Kurz, 2006). In their study of Latina women, those who immigrated to the United States as children were likely to experience higher rates of depressive and anxiety symptoms (Cordero \& Kurz, 2006). Regardless of these complexities, poverty, educational opportunity, geographical context, early childhood experiences, occupation, race, ethnicity and exposure to racism, availability of social support, and stress are factors generally agreed upon as having a strong relationship to health outcomes (Braveman, Egerter, \& Mockenhaupt, 2011).

Social determinants can include social factors directly related to a population's health (e.g., health behaviors such as healthy food choices) and those more indirectly related (e.g., access to affordable fresh produce and nutritional knowledge). The literature generally indicates broad categories of macro and indirect social factors, termed upstream determinants, and links them to microhealth behaviors, risks, and protective factors, referred to as downstream determinants (Braveman, Egerter, \& Mockenhaupt, 2011). These terms imply the relationship upstream determinants have in shaping downstream factors.

Maternal and infant health disparities have economic and social justice consequences. In the United States, diseases such as obesity, cardiovascular disease, and cancer consume more than $75 \%$ of the nation's health care (Wilensky \& Satcher, 2009). These diseases are shaped, at least 
in part, by early childhood experiences. When children are exposed to disparate environments and experiences, they enter a trajectory of mental and physical health disparities across the life course (Beddington et al., 2008; Wilensky \& Satcher, 2009).

Additionally, the intergenerational impact of health disparities has significant social justice implications. Researchers continue to discover the apparent complex pathways social determinants and health outcomes follow one generation to another. Interdisciplinary partnerships with the field of epigenetics provide evidence suggesting that social determinants may alter the genetic material passed from generation to generation (Walters, Beltrán, et al., 2011; Walters, Mohammed, et al., 2011). As marginalized groups experience poorer health outcomes due, in part, to the effects of structural oppression (e.g., racism, discrimination), the health of future generations within these groups is in jeopardy (Braveman, Egerter, \& Mockenhaupt, 2011; Walters, Beltrán, et al., 2011).

Thus, intergenerational disparities perpetuated through maternal and infant health are a central concern to social workers. The social work profession has a unique understanding of ecological context, biopsychosocial-spiritual health and holism, as well as a mandate to work on behalf of marginalized populations (National Association of Social Workers [NASW], 2008). Its ability to analyze and intervene in contextual factors, as well as engage in interdisciplinary work, leaves the social work profession well poised to make research and practice contributions in this area.

\section{Theoretical Conceptualization}

Social determinants of maternal and infant health may be examined through the life course perspective (LCP; Lu \& Halfon, 2003) and historical trauma (HT) theory (Brave Heart \& DeBruyn, 1998; Evans-Campbell, 2008; Sotero, 2006; Walters, Mohammed, et al., 2011; Walters \& Simoni, 2002). Both LCP and HT include a distinct focus on understanding the deeply contextualized lived experiences of marginalized groups as related to health disparities (Brave Heart \& DeBruyn, 1998; Lu \& Halfon, 2003; Pies et al., 2012; Sotero, 2006; Walters, Beltrán, et al., 2011; Walters, Mohammed, et al., 2011). As such, they suggest a need to include upstream social determinants in developing maternal and infant health strategies (Pies et al., 2012). Importantly, they also offer potential practice utility for social workers and other professionals engaged in this area. This article will explain the major premises of LCP and HT, provide application examples, compare and examine utility for practice, and highlight areas for future research. The article will include critique of these theories as well as insight into how they might be integrated to address respective gaps as an approach to maternal and infant health research and practice.

\section{$L C P$}

Emerging out of social determinant research, LCP provides a lens through which maternal and infant health disparities may be examined (Lu \& Halfon, 2003). The LCP was developed in response to inadequate explanations of persistent birth outcome disparities (Lu \& Halfon, 2003). It draws conceptually from two mechanisms demonstrating how the environment impacts development-early programming (Barker, 1990) and cumulative pathway (McEwen, 1998). Both the early programming and cumulative pathway mechanisms were developed out of findings from a large British birth cohort study conducted in the 1930s (Lu \& Halfon, 2003).

The early programming mechanism emerged from the Barker hypothesis, which posits that human development is particularly sensitive to experiences in early life, including certain prenatal and early childhood periods (Hogan et al., 2012; Lu \& Halfon, 2003). It further states that these early experiences have lifelong health consequences such as the development of diabetes mellitus and cardiovascular disease (Barker, 1990). Lu and Halfon (2003) deduced that if research identified a link between early experiences to the aforementioned conditions, reproductive health could also be 
impacted by early experiences. The cumulative pathway mechanism examines the ideas of accumulation and adaptation to chronic social and physical stressors, frequently referred to as "wear and tear" in the literature, on human development and health (Lu \& Halfon, 2003; McEwen, 1998; Pies et al., 2012). These stressors may include experiences such as homelessness, discrimination, infections, and health-related behaviors (e.g., smoking; Lu \& Halfon, 2003).

The LCP integrates both mechanisms as it proposes that women who experience chronic stress (e.g., recurrent experiences of racism and discrimination, displacement, intergenerational poverty) are at heightened risk for poor health outcomes especially when those experiences occur during critical developmental periods such as prenatal development, adolescence, and pregnancy (Lu \& Halfon, 2003; Pies et al., 2012). The more of these stressors women incur during critical periods, the higher the likelihood of poor health outcomes across the life course (Lu \& Halfon, 2003). This notion is bolstered by evidence of continuing maternal and infant health disparities among people of color and those living in poverty.

The LCP possesses an inherently holistic and ecological value system. It moves examination of health disparities away from a solely biomedical model and toward a more interdisciplinary, integrated approach. It also reflects cultural responsiveness and highlights the importance of the upstream social determinants of oppression, racism, and discrimination. This is important in the sense that it avoids blaming marginalized women for poor infant health outcomes. The LCP offers a framework for practitioners to conceptualize the social, physical, and environmental factors involved in maternal and infant health. While the theory lacks specificity in identifying the most salient factors related to maternal and infant health, it offers a starting point for a more holistic approach. It also necessitates that researchers, policy makers, and practitioners see their respective work as inherently interconnected and value interdisciplinary work that links micro and macro contexts.

\section{Application of LCP}

The LCP is shaping infant and maternal health research, policy, and practice (Berkman, 2009; Pies et al., 2012). Some providers of maternal and child health services are including this theory in their orientation to services, leading to consideration of broader ecological factors across the life course such as social support, housing, neighborhood safety, access to nutritious foods, and financial security (Pies et al., 2012). One such application is the Maternal and Child Health Program of Contra Costa Health Services (CCHS) in California. CCHS decided to modify the scale and provision of services due in large part to the realization that despite an impressive utilization of prenatal health services $(90 \%)$ within the county, birth outcome disparities continued to exist specifically for African Americans. In 2005, CCHS changed its approach to align with LCP, starting at the ground level by engaging community stakeholders, funders, and employees. Additionally, CCHS conducted a community-based participatory research (CBPR) project utilizing photovoice with consumers to gain understanding of what they perceived as important in addressing disparities (Pies et al., 2012).

This process led CCHS to focus services on some of the identified upstream determinants of health such as financial security, housing, violence, education, and access to quality nutrition (Pies et al., 2012). The "Building Economic Security Today" program, which focuses on increasing the financial security of women utilizing CCHS, emerged in response to the CBPR project as consumers identified financial security as a salient need. This asset development program provides financial education, individual support, and relevant referrals to participants. While research has yet to document a positive impact on maternal and infant health outcomes through addressing socioeconomic factors, increasing financial security may be one way to address the ways that structural oppression manifests. In a qualitative study examining the relationships between gender, employability, and health, Canadian women reported financial concerns as significant and chronic stressors affecting 
their health (Reid \& LeDrew, 2013). In 2011, researchers working with CCHS produced a report of the organization's effort to transform its approach (Pies et al., 2012). Empirical evidence supporting an LCP approach to CCHS's maternal and infant health program will likely take a considerable number of years. This reorientation of CCHS reflects a broad change with the ultimate goal of improving disparities in coming generations. Researchers continue to evaluate the LCP's approach to maternal and infant health as outcomes are collected; however, no current reports exist documenting outcomes to date (Pies et al., 2012).

\section{HT Theory}

HT theory provides an alternate lens for understanding social determinants by identifying the impact of traumatic events on the health outcomes of marginalized groups resulting from targeted oppression. It emerged from the study of Jewish Holocaust survivors as researchers explored the phenomenon that survivors' offspring were more likely than the general population to experience mental health conditions such as posttraumatic stress disorder, even though they had not directly experienced the Holocaust (Brave Heart \& DeBruyn, 1998; Danieli, 1998; Kellerman, 2001). This raised questions about the ability of generations to "inherit" mental and physical health conditions biologically as well as socially and culturally (Sotero, 2006). More recently, HT has been applied to Mexican Americans (Estrada, 2009) and AIAN (Brave Heart, 2003; Brave Heart \& DeBruyn, 1998; Walters, Beltrán, et al., 2011; Walters, Mohammed, et al., 2011; Walters \& Simoni, 2002).

An important distinction is the difference between the experience of HT and the subsequent HT response. Trauma literature generally supports that individuals may experience trauma but not develop associated trauma symptomology. A critique of HT literature is that it has yet to thoroughly examine resilience factors and mechanisms that enable some individuals within marginalized groups to avoid symptomology associated with historically situated traumatic events (Denham, 2008). Maria Yellow Horse Brave Heart, a primary scholar in HT literature, refers to a "constellation" of symptoms related to collective group loss and unresolved grief (Brave Heart, 1999b; Brave Heart \& DeBruyn, 1998).

HT theory proposes that health disparities experienced by certain populations reflect symptoms of historically situated experiences such as ancestral group traumatic loss (e.g. displacement, genocide, slavery; Brave Heart \& DeBruyn, 1998; Danieli, 1998; Denham, 2008; Kellerman, 2001; Sotero, 2006; Walters, Beltrán, et al., 2011; Walters, Mohammed, et al., 2011). Assumptions of this theory are that groups experience trauma systematically inflicted by a dominant group, the trauma extends for a period of time, the group subsequently experiences collective trauma, and the associated trauma response is transmitted to future generations (Brave Heart \& DeBruyn, 1998; Estrada, 2009; Sotero, 2006). Examples include survivors of the Jewish Holocaust (Danieli, 1998), the displacement and land loss experienced by the Lakota during the Wounded Knee Massacre (Brave Heart, 1999b; Brave Heart \& DeBruyn, 1998), the forced assimilation of Mexican Americans (Estrada, 2009), and the experience of displacement and slavery of African Americans (Sotero, 2006). HT symptomology includes both mental and physical health conditions such as depression, anxiety, suicide, substance abuse, cardiovascular disease, and diabetes (Brave Heart, 2003; Brave Heart \& DeBruyn, 1998; Walters, Beltrán, et al., 2011; Walters, Mohammed, et al., 2011; Walters $\&$ Simoni, 2002). These conditions mirror those found in health disparities literature, thus contributing support for HT theory.

\section{Application of HT Theory}

Maria Yellow Horse Brave Heart has had an instrumental role in developing applications of HT through research and practice. One such example is the Takini Network, a nonprofit organization 
located in South Dakota, founded in 1992 to promote healing from intergenerational and HT. Through the Takini Network, Brave Heart developed a psychoeducational curriculum with the goal of helping native people heal from unresolved grief and trauma resulting from collective, intergenerational loss (American Indians and Alaskan Natives in Health Careers, 2007). This curriculum has been adapted to meet the specific needs of different groups but includes several main components. Healing is promoted through intensive group work focused on learning about and naming historically traumatic events, as well as reattachment to native and cultural healing strategies such as rituals, songs, and other spiritual practices (Brave Heart, 1999a, 1999b, 2003). Evidence supports the effectiveness of interventions using the Takini Network resources in resolving grief, reducing anxiety, and empowering American Indians and Alaskan Natives to reclaim ancestral heritage (Brave Heart, 1999a, 2003).

Similarly, Brave Heart (1999b) developed a parenting group curriculum in which Lakota parent facilitators deliver the Wakanheja curriculum, named for the phrase "lena wukan heca-these children are sacred." Parents receive information related to HT and are encouraged to "reattach" to traditional Lakota values. In a qualitative study, parents reported the HT components of the curriculum particularly helpful to parenting (Brave Heart, 1999b). These findings are consistent with Tseris' (2013) feminist critique of providers' use of trauma theory. In her work, Tseris highlights the importance of considering sociopolitical context when engaging in trauma work, as well as the necessity of addressing themes of self-blame, power, betrayal, and stigma. While HT has not been examined specifically in the context of maternal and child health, these studies reflect its potential utility and suggest it may provide important contributions to the field of maternal and child health, particularly as it relates to disparities among marginalized groups.

\section{Theoretical Comparison and Critique}

The LCP and HT theory present opportunities to enhance research, policy, and practice related to social determinants of health. Conceptually, LCP and HT align with an ecological systems perspective, acknowledging that individual health occurs within a context of biological, psychological, social, and spiritual factors. They are congruent with trauma and stress literature, which provide insight into the physical, psychological, and interpersonal response to trauma and cumulative stress. The LCP and HT theory address health disparities represented in the literature. Constructs of HT (e.g., unresolved grief, trauma symptomology) fit with accepted theories of trauma and critical perspectives. Together, LCP and HT enhance conceptual understanding of the social factors impacting maternal and infant health disparities.

A notable difference is that LCP addresses the social factors related explicitly to maternal and infant health. The model was developed in response to maternal and infant health disparities (Lu \& Halfon, 2003), and it has gained favor among those researching and practicing in this area (Berkman, 2009; Hogan et al., 2012; Pies et al., 2012). The HT theory, however, was developed to explain overarching health disparities experienced by marginalized ethnic and racial groups (Brave Heart \& DeBruyn, 1998; Danieli, 1998). In taking a closer look, potential exists for HT to enhance the application of the LCP. While LCP effectively identifies ecological factors impacting maternal and infant health disparities, it fails to acknowledge the powerful impact of social and political history and the ways this history impacts health trajectories (Cordero \& Kurz, 2006; Hogan et al., 2012; Tseris, 2013). As LCP provides constructs related to early programming and cumulative stress, HT could enhance understanding of the specific social and historical factors involved in cumulative stress.

Another point of comparison between LCP and HT theory is in how directly each addresses the social determinant of poverty as it relates to health disparities. The literature clearly identifies socioeconomic status as salient in understanding health disparities (Braveman, Egerter, \& Mockenhaupt, 2011; Braveman, Egerter, Woolf, \& Marks, 2011; Miller, Pollack, \& Williams, 2011; Wilensky \& Satcher, 2009). 
The LCP addresses cumulative stressors directly related to poverty that may impact health during critical developmental periods. For example, LCP identifies early educational experiences, exposure to violence, perceived safety, health care access, exposure to environmental toxins, and housing conditions as chronic stressors related to socioeconomic status. The HT theory, however, includes poverty as an indirect factor associated ultimately with targeted structural oppression; the focus of HT is unapologetically on historically situated traumatic experiences rather than socioeconomic status. This becomes relevant in considering its utility in research, policy, and practice that often directly identifies those living in poverty as a target population.

HT theory challenges dominant group subjugation and magnifies the social and political history contextualizing the lived experiences of marginalized groups, as they relate to race, ethnicity, and socioeconomic status. It suggests, for example, that conceptualization of the Lakota is inadequate without understanding the Wounded Knee Massacre and its intergenerational psychological, spiritual, and biological impact (Brave Heart, 2003). This may be the most useful intersection point of HT and LCP, given that LCP lacks depth and specificity in this area. Applying HT's constructs of social and political history to enhance the LCP could be highly valuable. Research demonstrates that even though socioeconomic status remains a salient social determinant of health, the effects of racial and ethnic marginalization remain powerful determinants as well. Thus, HT may more effectively address the needs of racially and ethnically marginalized groups.

An additional point of comparison is the degree to which LCP and HT parsimoniously identify and designate relationships between constructs. By nature of explaining cumulative lifetime stressors and historically situated experiences, both LCP and HT possess challenges in their ability to gather empirical support and develop clear causal models. Additionally, both inherently deal with the complex intersection of gender, class, race, and ethnicity; disentangling these constructs is difficult, especially within a longitudinal study. For example, Reid and LeDrew (2013) identify gender, place, the local economy, and cultural identity as intersecting factors that affect women's health and well-being and suggest the value of an intersectional framework. An additional hurdle is the content area itself rather than theoretical constraints. Social determinants research requires funding for longitudinal work, scholars who will engage in longitudinal work without the opportunity for immediate publication, interdisciplinary partnerships, operationalization of social factors, and more advanced measurements of infant and particularly maternal health (Braveman, Egerter, \& Williams, 2011).

The lack of clarity for both LCP and HT raise important questions. The LCP identifies abstract concepts such as the accumulation of stress, but it does not consistently state how this is operationalized and measured. Similarly, scholars do not agree on what constitutes a "sensitive period" of development. Are these limited to times such as prenatal development, early childhood, adolescence, and pregnancy? Which periods are most important, and are humans sensitive to the same exposures and experiences during each of these periods? Additionally, scholars must clarify if the LCP proposes universality of critical periods (Berkman, 2009). The HT theory suggests the impact of massive unresolved grief and ancestral loss on subsequent generations, but defining exactly who is impacted and how is unclear at times (Denham, 2008). Interdisciplinary partnerships with epigenetics may help identify transfer mechanisms, but important questions around risk and protective factors will likely remain.

Nonetheless, opportunities exist within both LCP and HT to address the needs of marginalized groups through research and practice, a focus of the social work profession (NASW, 2008). Though not abundant, the literature includes innovative applications of both LCP and HT theories. Applying LCP or HT in pursuit of more favorable maternal and infant health outcomes requires creativity and willingness to perhaps concede health service practices centered solely on Western medical models. The Takini Network is a prime example of efforts to support healing practices meaningful to American Indians rather than focusing primarily on Western medical models of healing (e.g., individual counseling, psychiatric care; American Indians and Alaskan Natives in Health Careers, 2007). The 
CCHS offers an alternative approach as well—one more focused on women's ecology, biopsychosocial health, and long-term health outcomes (Pies et al., 2012).

Despite the aforementioned challenges for LCP and HT theory, strength lies in their innovativeness and practice utility. Currently, LCP and HT present fresh ways of understanding maternal and infant health. Each moves the focus of research and practice away from a myopic view of downstream social determinants and suggest a broader, more ecological and holistic perspective. They magnify the powerful ways health disparities reflect the impact of oppression, racism, and discrimination. The HT theory, in particular, necessitates examination of past and present oppression. As the literature continues to demonstrate that maternal and infant health disparities are likely influenced by interdependent factors, the LCP and HT theory potentially enhance research, policy, and practice opportunities by allowing for such complexity.

The enhancement of LCP with HT concepts is not seen in the literature and offers an alternative approach to research and intervention. Further research and practice conducted through providers of maternal and infant health services could include elements of HT theory. These might include interventions designed to acknowledge historically traumatic events and address unresolved grief and trauma symptomology for groups such as AIAN, Mexican Americans, and African Americans. If empirical evidence can provide support for an LCP approach enhanced by HT, maternal and infant health services may expedite progress toward minimizing disparities. This work could further legitimize the devastating impact of historically traumatic experiences, racism, and discrimination on health outcomes, and change practice paradigms toward more culturally responsive models. In this way, upstream social determinants reflecting power inequalities could become more central to policy advocacy rather than being driven primarily by downstream determinants. This could ultimately lead to the disruption of disparities and move future generations of marginalized groups along a positive health trajectory.

\section{Conclusion}

While the examination of social determinants of maternal and infant health disparities has gained credibility among scholars, it remains in an early period of development. The literature in this area continues to gather evidence, define constructs, develop conceptual models, and apply theories to practice. Research of LCP and HT theory, though promising, also possess significant knowledge gaps. These include the specific identification of upstream and downstream determinants, empirical support, specific applications to maternal and infant health, and identification of resilience and protective factors.

Attending to the different and at times complex intersections between upstream and downstream determinants is paramount in guarding against the blaming of individuals and cultural groups for poor health outcomes. These determinants must be thoughtfully framed so that individual and cultural behavioral choices are acknowledged when necessary (e.g., educating women to choose nutritional food choices when possible), but that the emphasis remains on the upstream factors shaping these behaviors (Tseris, 2013). The social work profession must exercise care when describing the meaning of social determinants to students, providers, and consumers.

A significant gap in the literature includes empirical support for LCP and HT. As mentioned earlier, this reflects multifaceted challenges including research funding, higher education institutional culture, theoretical development, and the need for interdisciplinary research. Social workers engaged in the area of maternal and infant health disparities must partner with those from other disciplines and seek funding streams that enable researchers to disentangle concepts through longitudinal research and gather empirical support (Braveman, Egerter, \& Williams, 2011).

A related research gap involves examining the application of LCP and HT theory to maternal and infant health outcomes. While CCHS built support for the LCP theory as an approach to maternal 
and infant health within the community and organization itself, how it actually changed its existing services is unclear, and health outcomes reflective of the changed approach have not yet been established. Findings from CCHS and others applying the LCP will ultimately build empirical support for this approach. Similarly, a research gap exists in the application of HT theory to maternal and infant health. Other maternal and infant health programs serving AIAN, African Americans, and Mexican Americans could logically apply HT to services, measuring its effectiveness in reducing disparities. Finally, the enhancement of LCP with concepts from HT as presented earlier is unidentified in the research as a practice strategy. Examination of this idea could lend valuable information to the field of maternal and infant health.

A final gap in the literature is the exploration of maternal and infant health resilience respective to LCP and HT. The identification of protective factors would aid efforts to cultivate resilience among women and children (Denham, 2008; Tseris, 2013). This work faces some of the challenges listed previously, beginning with disentangling social factors from one another and their longitudinal impact. As LCP and HT continue to define and measure constructs, scholars must identify relationships between factors that build resilience and protection.

An enhanced LCP and HT approach contributes to the literature concerning maternal and infant health disparities. This approach has the potential to identify protective factors for marginalized groups and move toward a more strengths-based, culturally responsive, and holistic approach to maternal and infant health. Based on this potential, social workers could reasonably advocate for an integrated approach to addressing maternal and infant disparities. A possible starting point would be incorporating HT interventions in programs already utilizing the LCP. This would require adapting HT interventions, such as the psychoeducational curriculum identified through the Takini Network, to other ethnic and racially marginalized groups. The enhancement of LCP with HT concepts will likely need to be adapted for the particular group in question. For example, factors associated with health outcomes for the Lakota or Mexican Americans will likely be as unique as their social and political histories. This will require considerable cultural knowledge and creativity for practitioners.

Scholarship opportunities are rich in the areas of theory and intervention research, and ultimately policy work. Social workers are particularly well positioned to make contributions toward reducing maternal and infant health disparities through research, policy, and practice. Theoretical constructs, along with the relationships between them, must be clearly defined and measured. Interventions congruent with these constructs must be developed, evaluated, and disseminated. As empirical support grows, policy advocates must push for change reflective of findings so that the cycle of intergenerational health disparities may be interrupted.

\section{Acknowledgment}

The author would like to acknowledge Dr. Ramona Beltrán, DU GSSW faculty and Historical Trauma Theory expert, for her guidance and inspiration in completing this manuscript.

\section{Declaration of Conflicting Interests}

The author declared no potential conflicts of interest with respect to the research, authorship, and/or publication of this article.

\section{Funding}

The author received no financial support for the research, authorship, and/or publication of this article.

\section{References}

Ahnquist, J., Wamala, S. P., \& Linstrom, M. (2012). Social determinants of health: A question of social or economic capital? Interaction effects of socioeconomic factors on health outcomes. Social Science \& Medicine, 74, 930-939. 
American Indians and Alaskan Natives in Health Careers. (2007). Social work: Profiles, Maria Yellow Horse Brave Heart. Retrieved from http://aianhealthcareers.org/page7/page81/page95/page95.html

Barker, D. J. P. (1990). Fetal and infant origins of adult disease. British Medical Journal, 301, 1111.

Beddington, J., Cooper, C. L., Field, J., Goswami, U., Huppert, F. A., Jenkins, R., ... Thomas, S. M. (2008, October 23). The mental state of nations. Nature, 455, 1057-1060.

Berkman, L. F. (2009): Social epidemiology: Social determinants of health in the United States: Are we losing ground? Annual Review of Public Health, 30, 27-41.

Brave Heart, M. Y. H. (1999a). Gender differences in the historical trauma response among the Lakota. Journal of Health \& Social Policy, 10, 1-21.

Brave Heart, M. Y. H. (1999b). Oyate ptayela: Rebuilding the Lakota nation through addressing historical trauma among Lakota parents. Journal of Human Behavior in the Social Environment, 2, 109-126.

Brave Heart, M. Y. H. (2003). Historical trauma response among natives and its relationship with substance abuse: A Lakota illustration. Journal of Psychoactive Drugs, 35, 7-13.

Brave Heart, M. Y. H., \& DeBruyn, L. M. (1998). The American Indian holocaust: Healing historical unresolved grief. The Journal of the National Center, 8, 55-73.

Braveman, P. (2011). Black-White disparities in birth outcomes: Is racism-related stress a missing piece of the puzzle? In A. J. Lemelle, W. Reed, \& S. Taylor (Eds.), Handbook of African American health: Social and behavioral interventions (pp. 155-163). New York, NY: Springer.

Braveman, P. A., Egerter, S. A., \& Mockenhaupt, R. E. (2011). Broadening the focus: The need to address the social determinants of health. American Journal of Preventative Medicine, 40, S4-S18.

Braveman, P., Egerter, S., \& Williams, D. R. (2011). The social determinants of health: Coming of age. Annual Review of Public Health, 32, 381-398.

Braveman, P. A., Egerter, S. A., Woolf, S. H., \& Marks, J. S. (2011). When do we know enough to recommend action on the social determinants of health? American Journal of Preventive Medicine, 40, S58-S66.

Burgess, D. J., Ding, Y. , Hargreaves, M., van Ryn, M., \& Phelan, S. (2008). The association between perceived discrimination and underutilization of needed medical and mental health care in a multi-ethnic community sample. Journal of Health Care for the Poor and Underserved, 19, 894-911.

Cordero, A., \& Kurz, B. (2006). Acculturation and the mental health of Latina women in the women, infant, and children program. Affilia, 21, 46-58.

Danieli, Y. (Ed.). (1998). International handbook of multigenerational legacies of trauma. New York, NY: Kluwer Academic/Plenum Publishing.

Denham, A. R. (2008). Rethinking historical trauma: Narratives of resilience. Transcultural Psychiatry, 45, 391-414.

Estrada, A. L. (2009). Mexican Americans and historical trauma theory: A theoretical perspective. Journal of Ethnicity in Substance Abuse, 8, 330-340.

Evans-Campbell, T. (2008). Historical trauma in American Indian/Native Alaska communities: A multilevel framework for exploring impacts on individuals, families, and communities. Journal of Interpersonal Violence, 23, 316-338.

Hogan, V. K., Rowley, D., Bennett, T., \& Taylor, K. D. (2012). Life course, social determinants, and health inequities: Toward a national plan for achieving health equity for African American infants-A concept paper. Maternal and Child Health Journal, 16, 1143-1150.

Kellerman, N. P. F. (2001). Transmission of holocaust trauma: An integrative view. Psychiatry, 64, 256-267.

Lu, M. C., \& Halfon, N. (2003). Racial and ethnic disparities in birth outcomes: A life-course perspective. Maternal and Child Health Journal, 7, 13-30.

McEwen, B. S. (1998). Protective and damaging effects of stress mediators. The New England Journal of Medicine, 338, 171-179.

Miller, W. D., Pollack, C. E., \& Williams, D. R. (2011). Healthy homes and communities: Putting the pieces together. American Journal of Preventative Medicine, 40, S48-S57. 
National Association of Social Workers. (2008). Preamble to the code of ethics. Retrieved October 26, 2012, from http://www.socialworkers.org/pubs/code/code.asp

Pies, C., Parthasarathy, P., \& Posner, S. (2012). Integrating the life-course perspective into a local maternal and child health program. Maternal and Child Health Journal, 16, 649-655.

Reid, C., \& LeDrew, R. A. (2013). The burden of being "employable": Underpaid and unpaid work and women's health. Affilia, 28, 79-93.

Sotero, M. M. (2006). A conceptual model of historical trauma: Implications for public health practice and research. Journal of Disparities Research and Practice, 1, 93-108.

Tseris, E. J. (2013). Trauma theory without feminism? Evaluating contemporary understandings of traumatized women. Affilia, 28, 153-164.

Walker, L. O., \& Chesnut, L. W. (2010). Identifying health disparities and social inequities childbearing women and infants. Journal of Obstetric, Gynecologic, and Neonatal Nursing, 39, 328-338.

Walters, K. L., Beltrán, R., Huh, D., \& Evans-Campbell, T. (2011). Dis-placement and dis-ease: Land, place, and health among American Indians and Alaska Natives. In L. M. Burton, S. A. Matthews, M. C. Leung, S. P. Kemp, \& D. T. Takeuchi (Eds.), Communities, neighborhoods, and health, social disparities in health and health care I (pp. 163-199). New York, NY: Springer.

Walters, K. L, Mohammed, S. A., Evans-Campbell, T., Beltrán, R. E., Chae, D. H., \& Duran, B. (2011). Bodies don't just tell stories, they tell histories: Embodiment of historical trauma among American Indians and Alaska Natives. Du Bois Review, 8, 179-189.

Walters, K. L., \& Simoni, J. M. (2002). Reconceptualizing native women's health: An “indigenous" stress coping model. American Journal of Public Health, 92, 520-524.

Webb, R. (2004). Health disparities practice update: Reproductive health disparities for women of color. Human Rights and International Affairs. Washington, DC: National Association of Social Workers.

Wilensky, G. R., \& Satcher, D. (2009). Don't forget about the social determinants of health. Health Affairs, 28, w194-w198.

\section{Author Biography}

Susanne Klawetter, LCSW, is a doctoral student at the University of Denver's Graduate School of Social Work interested in examining social determinants of maternal and child health disparities. She is currently a JFK Partners Leadership Education in Neurodevelopmental Disabilities (LEND) Fellow with the University of Colorado, School of Medicine. 